\title{
Measuring handicap: the London handicap scale, a new outcome measure for chronic disease
}

\author{
Rowan H Harwood, Angela Rogers, Edward Dickinson, Shah Ebrahim
}

\begin{abstract}
Objective-To develop a handicap measurement scale in a self completion questionnaire format, with scale weights allowing quantification of handicap at an interval level of measurement.

Design-Adaptation of the International Classification of Impairments, Disabilities and Handicaps into a practical questionnaire incorporating the dimensions of handicap mobility, occupation, physical independence, social integration, orientation, and economic self sufficiency and scale weights derived from interviews with a general population sample, with the technique of conjoint analysis.

Setting-Two general practices in different areas of London.

Subjects-240 adults aged 55-74 years randomly selected from the practices, 101 $(42 \%)$ of whom agreed to be interviewed, and $79(78 \%)$ of whom completed the exercise.
\end{abstract}

Main measures-Rating of severity of handicap associated with 30 hypothetical health scenarios on a visual analogue scale, from which was derived a matrix of scale weights ("part utilities") relating to different levels of disadvantage on each dimension, with a formula for combining them into an overall handicap score. Severity scores measured directly for five scenarios not used to derive the scale weights were compared with those calculated from the formula to validate the model.

Results-The part utilities obtained conformed with the expected hierarchy for each dimension, confirming the validity of the method. The measured severities and those calculated from the formula for the five scenarios used to validate the model agreed closely (Pearson's $r=0.98$, $p=0.0009 ; \quad$ Kendall's tau $=1.00, \quad p=$ 0.007).

Conclusions-This interval level handicap measurement scale will be useful in assessing both specific therapies and health services, in clinical trials, in analyses of cost effectiveness, and in assessments of quality assurance.

(Quality in Health Care 1994;3:11-16)

\section{Introduction}

The need for measures of morbidity to complement mortality statistics has led to much work on the development of scales measuring disability, health, and quality of life. ${ }^{12}$ Such scales must make valid assessments of the effects of many different conditions or combinations of conditions. McDowell and Newell argued that "health indices should measure a specific and defined aspect of health, generally defined in terms of a specific concept or theory". 'When considering the consequences of chronic disease, the International Classification of Impairments, Disabilities and Handicaps (ICIDH $)^{3}$ provides a suitable framework for conceptualising a measurement scale. Handicap is defined as the disadvantage for a given individual, resulting from ill health that limits or prevents the fulfilment of a role that is normal (depending on age, sex, and social and cultural factors) for that individual. Reducing handicap is the key goal of management in chronic illness, and, as such, measuring handicap is required for assessing need, for quality assurance, and for evaluating interventions for research. An accompanying paper (p 53) ${ }^{4}$ describes in more detail the measurement of handicap and the basis of this reported study.

We aimed at developing a questionnaire to classify handicap from the descriptive system presented in the ICIDH and measuring severity weightings for states described by the classification to produce an interval-level scale. The questionnaire was designed to facilitate self completion (or completion by a carer) in postal surveys.

\section{Methods}

HANDICAP CLASSIFICATION QUESTIONNAIRE The ICIDH defines six dimensions for handicap: mobility, orientation, physical independence, occupation, social integration, and economic self sufficiency. Handicap is classified according to which of nine levels of disadvantage an individual corresponds on each of the dimensions. For practicality the number of levels in each dimension in the questionnaire was reduced to six. Each level was represented by a short description outlining disadvantage in terms of what someone does or does not do. The classification questionnaire therefore comprised six questions (one for each dimension), and each question asked the respondent to choose which of the six descriptions was nearest to his or her own situation.

The questionnaire was submitted to a rigorous process of examination and pilot testing by professional and lay subjects to ensure simplicity and clarity and to avoid jargon and ambiguity while remaining faithful to the classification categories laid down by 
the ICIDH. To this end the questionnaire was called "Your Health and Your Life" as the terms handicap and disadvantage were found in the pilot to be off putting. Similarly, the different sections were renamed "getting around," "looking after yourself," "work and leisure," "getting on with people," "awareness of your surroundings," and "affording the things you need." Statements were made objective enough to enable carers to complete the questionnaire on behalf of people with visual, cognitive, or communication difficulties, if necessary.

DERIVATION OF SCAILE WEIGHTS

The classification scheme potentially allows $46656(6 \times 6 \times 6 \times 6 \times 6 \times 6)$ different states to be described. To create a quantitative measurement scale from the classification the severity of handicap associated with each of these states has to be determined. Clearly, direct measurement of so many states is impossible. A method of estimation of severities is required, and this forms the basis of the handicap scale. We used a technique designed for use in market research called conjoint analysis. ${ }^{j}$ This technique requires direct measurements of the severity of only a small sample of possible states, from which commercially available computer software" calculates a matrix of scores ("part utilities") associated with each level of each dimension. These part utilities can be combined in a mathematical model to estimate the overall severity of any combination of levels.

The number of measurements required to build a model with conjoint analysis depends on the number of levels in each dimension. Six dimensions each with six levels would require 49 measurements. This number was too large for measurement interviews to be tolerable or practical. Consequently, only four levels were used in each dimension, requiring subjects to give ratings of only 25 different states. Five additional "test scenarios" were included to validate the model.

Each level in each dimension was represented by a short statement of abilities and limitations. Combinations of these statements were used to construct multidimensional scenarios. The clarity of the statements was tested by asking a sample of nine health professionals to classify each one to the ICIDH handicap codes. Ninety per cent of classifications were in agreement with each other. This process was also used to identify which two of the six levels were "missing." The box shows an example of a multidimensional scenario.

We asked subjects ("judges") to rate the severity of disadvantage of each scenario on a visual analogue rating scale. Each was given a score between zero (no disadvantage) and 14 (worst imaginable disadvantage). The ends of the scale were anchored by appending scenarios comprising the six least disadvantaged levels at one end and the six most disadvantaged levels at the other. The reliability with which these assessments could be made was tested in a pilot study in which nine health professionals repeated a rating

\begin{tabular}{|c|c|}
\hline \multicolumn{2}{|c|}{$\begin{array}{l}\text { Example of a multidimensional } \\
\text { scenario }\end{array}$} \\
\hline Mobility & $\begin{array}{l}\text { You can go where you } \\
\text { want to go but it's not } \\
\text { easy }\end{array}$ \\
\hline Physical independence & $\begin{array}{l}\text { You need help with } \\
\text { shopping and heavier } \\
\text { housework }\end{array}$ \\
\hline Occupation & $\begin{array}{l}\text { You can do everything } \\
\text { you want to do to } \\
\text { keep yourself occupied }\end{array}$ \\
\hline Social integration & $\begin{array}{l}\text { You feel comfortable } \\
\text { only with those people } \\
\text { whom you know well }\end{array}$ \\
\hline Orientation & $\begin{array}{l}\text { You know fully what is } \\
\text { going on in the world } \\
\text { around you }\end{array}$ \\
\hline $\begin{array}{l}\text { Economic self } \\
\text { sufficiency }\end{array}$ & $\begin{array}{l}\text { You have little money } \\
\text { only enough for your } \\
\text { most basic needs }\end{array}$ \\
\hline
\end{tabular}

exercise twice, a fortnight apart. The mean test-retest difference was less than one category.

The judges for the scaling study were 120 men and 120 women aged between 55 and 74 years randomly selected from the age-sex registers of two general practices in London and invited to take part. They were approached by letter and then by telephone and were asked to complete an interview with a researcher, who visited them at home. Each subject was asked to estimate the severity of disadvantage represented by each of the thirty multidimensional scenarios.

Data were entered on to a computer and analysed with SPSS/PC+. The levels within each dimension were entered as categorical entries, no assumption being made about the ordering of, or intervals between, successive levels. Models were created for each respondent along with an aggregated summary comprising the means of the coefficients. The goodness of fit of the models was tested by calculating correlation coefficients (Pearson's $r$ ) and coefficients of concordance (Kendall's tau) between measured and calculated scores. The validity of the model was tested by comparing calculated scores with those directly measured for the five "test scenarios." As six levels of disadvantage were defined for each dimension and only four levels were measured, the two missing levels were linearly interpolated.

\section{Results}

HANDICAP CLASSIFICATION QUESTIONNAIRE The questionnaire is shown at the end of this paper.

SCALE WEIGHTS

Of the 240 subjects invited to take part, $101(42 \%)$ agreed and of these, $79(78 \%)$ completed the interview, 48 of whom were women (mean age 65) and 31 of whom were men (mean age 67). Eighteen respondents described their health as "excellent," 36 as "good," 20 as "fair," five as "poor," and none as "bad." Thirty three respondents lived in 
rented accommodation and 46 were owner occupiers. The interviews took from 45 minutes to two hours to complete.

Table 1 shows the part utilities obtained from subjects' ratings. These are the scores which, when combined, give the best fit to the data which were actually measured for the 25 sample multidimensional scenarios. The model for calculating the severity of handicap is given by:

$$
\begin{gathered}
\text { Handicap }=0.456+u_{m}+u_{p i}+u_{o c} \\
+u_{s i}+u_{o r}+u_{e s s},
\end{gathered}
$$

where 0.456 is a constant and $u_{m}, u_{p i}, u_{o c}, u_{s i}$, $\mathrm{u}_{\mathrm{or}}$, and $\mathrm{u}_{\mathrm{ess}}$ are the part utilities of the appropriate level of each dimension in table 1 (mobility, physical independence, occupation, social integration, orientation, and economic self sufficiency). The constant which was initially calculated gave a range of predicted utilities of -0.25 to 0.75 . In an interval level scale the absolute values are arbitrary, so the constant was adjusted to give a range of 0 to 1 for simplicity of interpretation.

For example, if a subject were to indicate on the questionnaire that he or she was in the state of health described in the box the severity of handicap would be calculated as follows:

$$
\begin{gathered}
0.456+0.038-0.021+0.099-0.022 \\
+0.109-0.023
\end{gathered}
$$

This gives on overall handicap score of $0 \cdot 64$. If a subject is at no disadvantage in all dimensions the equation gives a score of $1 \cdot 00$.

Despite not prespecifying the order of the levels in the analysis the expected hierarchy was preserved for each dimension, confirming the validity of the process. The subjects viewed social integration as less important than other aspects of handicap since the range of scores associated with social integration items was smaller than for any of the other dimensions. They found mobility, orientation handicap, and economic self-sufficiency of greatest concern. For example, the best orientation level contributes to overall utility by adding $0 \cdot 109$, whereas the best social integration level added only $0 \cdot 063$. The worst economic self sufficiency level decreased overall utility by 0.111 whereas the worst social integration level decreased it by 0.041 . It can also be seen from this that some levels

\begin{tabular}{|c|c|c|c|c|c|c|}
\hline & \multicolumn{6}{|c|}{ Part utility associated with level of disadvantage ${ }^{\star}$} \\
\hline & 1 & 2 & 3 & 4 & 5 & 6 \\
\hline Mobility ("getting around") & 0.071 & 0.038 & 0.000 & -0.036 & -0.072 & $-0 \cdot 108$ \\
\hline $\begin{array}{l}\text { Physical independence } \\
\text { ("looking after yourself") }\end{array}$ & $0 \cdot 102$ & $0 \cdot 011$ & $-0 \cdot 021$ & -0.053 & -0.057 & $-0 \cdot 061$ \\
\hline $\begin{array}{l}\text { Occupation ("work and } \\
\text { leisure") }\end{array}$ & $0 \cdot 099$ & -0.004 & $-0 \cdot 014$ & -0.024 & -0.035 & $-0 \cdot 060$ \\
\hline $\begin{array}{l}\text { Social integration ("getting } \\
\text { on with people") }\end{array}$ & 0.063 & 0.035 & 0.007 & $-0 \cdot 022$ & $-0 \cdot 029$ & $-0 \cdot 041$ \\
\hline $\begin{array}{l}\text { Orientation ("awareness } \\
\text { of your surroundings") }\end{array}$ & $0 \cdot 109$ & -0.008 & -0.038 & -0.051 & -0.063 & $-0 \cdot 075$ \\
\hline $\begin{array}{l}\text { Economic self sufficiency } \\
\text { ("affording the things } \\
\text { you need") }\end{array}$ & $0 \cdot 100$ & 0.067 & 0.033 & -0.023 & -0.067 & $-0 \cdot 111$ \\
\hline
\end{tabular}
of disadvantage in each dimension (those with negative part utilities, table 1) increased the

Table 1 Matrix of scale weights (part utilities)
Table 2 Validity of model

\begin{tabular}{lcc}
\hline Test scenario & Calculated handicap & Measured handicap \\
\hline 1 & 0.61 & 0.67 \\
2 & 0.22 & 0.32 \\
3 & 0.67 & 0.72 \\
4 & 0.56 & 0.53 \\
5 & 0.42 & 0.45 \\
\hline
\end{tabular}

severity of perceived handicap whereas other levels (those with positive scores) mitigate the effects of problems in other dimensions. Thus for a given combination of problems in the five other dimensions, being completely independent of all human help (physical independence level 1) increased overall utility by $0 \cdot 102$ (that is, decreased perceived severity) whereas requiring constant attention (level 6) decreased overall utility by $0 \cdot 061$.

\section{VALIDITY OF MODEL}

Five "test scenarios" not used in formulating the model were used to check that the model gave reasonable estimates of severity for health states other than those used to derive it. Comparisons between calculated and directly measured severities showed good agreement (table 2). Pearson's correlation coefficient ( $r$ ) between predicted and measured values was 0.98 ( $p=0.0009)$, and Kendall's coefficient of concordance (tau) was $1.00(p=0.007)$. The model is thus able to predict the severity of handicap for any health state from the data collected on the subjects' opinions of the 25 sample states.

\section{Discussion}

We described a scale for measuring handicap based on the definition and classification system given in the ICIDH. Such a scale is required as an outcome measure for assessing need and evaluating new and existing services for people with chronic ill health and disability. Essentially we rewrote the ICIDH classification system in a format suitable for data collection in postal surveys and carried out an exercise on severity weighting in 79 middle aged and elderly subjects who were resident at home. This group suffers the greatest burden of disability, ${ }^{7}$ and, consequently, is appropriate for weighting a handicap measurement scale. The intention is that the part utilities obtained in this study can be used to weight responses in the questionnaire when it is used in future studies.

Several aspects of the weighting exercise need consideration. Despite using six levels of disadvantage on each dimension in an attempt to maximise sensitivity to change it was possible to use only four of these in the weighting exercise. Successful interviews were obtained from only $33 \%$ of the 240 subjects initially approached, although $79 \%$ of those who agreed to take part completed the interview. It is most likely that the prospect of a long interview for which there was no apparent reward or benefit for the individual was the major reason for subjects not agreeing to take part. Those who were unwilling would probably comprise people with more adverse 
health behaviours but there is no reason to believe that the utilities they would place on handicap states would differ systematically from those of the subjects who did take part. Earlier work showed that the utilities given to a sample of health states (defined by the Rosser-Kind disability and distress dimensions ${ }^{8}$ ) were not appreciably altered by age or disability. ${ }^{9}$ In our study, although the relative importance of different dimensions differed greatly between individuals, there were no systematic differences with age, sex, health, practice, and housing tenure or in comparison with a group of 14 health professionals. There is no ideal population for determining scale weights; whether more weight should be given to the views of disabled people, professionals, or any other group is essentially political and not technical.

The interviews were probably about as difficult as it is reasonable to expect lay subjects to undertake, and the inaccuracy introduced as a result of interpolating part utilities for some levels is the price of obtaining the opinions of a reasonable number of the lay public. The response rate was no worse than that achieved in other similar utility scaling studies, ${ }^{10}$ and this study had the virtue of having canvassed the opinions of the general public as opposed to the health professionals, students, or patients used in some other studies. ${ }^{78}$

The model which initially emerged from the conjoint analysis gave a range of predicted scores which included some negative values. This suggests that despite the attempt to anchor the most disadvantaged end of the visual analogue scale on the most disadvantaged scenario which could be described by the system used, the responses given for scenarios which were measured clustered towards the end of the scale and implied the possibility of combinations which went beyond the end of the scale. With combinations of very severe disadvantages a simple additive linear model may well be inadequate. However, the absolute values on an interval scale are arbitrary, and the five scenarios used to test the model gave good agreement between measured and predicted scores over a reasonable range of severity, so a 0-1 range was ensured by adjustment of the constant in the model. The negative values cannot be interpreted as "worse than death" states as they are in some other scales. It was considered that the concept of "disadvantage" being associated with death was untenable, and so death was not included among the scenarios.

Although the scaling exercise was difficult, the questionnaire completed by patients (or their carers) is very easy to complete, comprising just six questions. The questionnaire descriptions emphasise what someone is able to achieve in everyday life in their normal physical environment, regardless of the help that might be required in the form of human help, aids, or adaptations. For example, mobility is the ability to get from one place to another. Someone might have a mobility handicap as a result of being unable to walk after an accident or a stroke. Clearly, in rehabilitation the desired goal is that someone be able to achieve independent mobility (for example learning to walk again). However, if that is not possible, instruction in the use of a wheelchair and a wheelchair-adapted vehicle can reduce disadvantage. And if that is not possible, owning a car and having a spouse with the time and inclination to drive it wherever the subject wants to go leaves that subject less disadvantaged in terms of mobility than others who do not have these things.

There is a disadvantage associated with being reliant on aids or another person for help, and this was subsumed under the heading of physical independence handicap rather than any other dimension. Since many basic physiological, domestic, and hygiene needs must be met somehow for someone to survive, the level of dependence in these can be used to describe physical independence in general. Economic self sufficiency embraces both the effects of ill health on the ability to earn a living and the ability to use wealth to overcome disadvantages associated with ill health. These definitions differ slightly from those originally used in the ICIDH (the requirement for help in any one dimension was deemed to be a disadvantage in that dimension) but were required to keep the questions mutually exclusive and relatively independent for the scaling exercise.

The London handicap scale has practical uses both in measuring outcomes of clinical trials entailing comparisons of group mean handicap scores in intervention and placebo (or control) groups, by using either the overall score or the dimension specific scores, and in observational epidemiology. The scale might also be used to monitor the case mix between services when comparisons of outcomes are made using observational methods. Caution must be observed when applying the scale to examine changes in individual patients for clinical assessment as the scale does not aim at measuring an individual subject's handicap (which is unique to that person) but uses the views of the general population. The scale is therefore meant for comparisons between groups of subjects, although the extent to which handicap scores reflect the true handicap experienced by an individual will be determined by the degree of difference between the individual and the general population. An initial investigation of the construct validity of the scale in stroke and rheumatoid arthritis patients has been undertaken. ${ }^{11}$

Finally, postal administration of questionnaires is a useful way of collecting data on a large scale, cheaply, and with only indirect professional interpretation of a subject's experiences. The London handicap scale is available from the authors, who would be pleased to help any prospective users.

This study was funded in part by REMEDI and The Sandoz Foundation for Gerontological Research. Dr Jeremy Shindler and Dr Chris Dobbing selected the subjects from their age-sex 
registers; Dr Patrick Gompertz and Ms Pandora Pound made many helpful comments on the wording of the questionnaire. $\mathrm{RHH}$ is an MRC health services research training fellow.

1 McDowell I, Newell C. Measuring health: a guide to rating scales and questionnaires. New York: Oxford University Press, 1987;26.

2 Walker SR, Rosser RM. Quality of life: assessment and application. Lancaster: MTP Press, 1988.

3 World Health Organisation. International classification of impairments, disabilities and handicaps. Geneva: WHO,

4 Harwood RH, Jitapunkul S, Dickinson E, Ebrahim S Measuring handicap: motives, methods, and a model Quality in Health Care 1994;3:53-7.
5 Churchill GA. Marketing research: methodological foundations, 3rd ed Chicago: Dryden Press, 1989.

6 SPSS. SPSS categories. Chicago: SPSS, 1990.

Martin J, Melzer $\mathrm{H}$, Elliot $\mathrm{D}$. The prevalence of disability among adults. OPCS Social Survey division. London HMSO, 1988

8 Rosser RM, Kind P. A scale of valuations of states of illness: is there a social consensus? Int 7 Epidemiol 1978;7: 347-58.

9 Ebrahim S, Brittis S, Wu A. The valuation of states of illhealth: the impact of age and disability. Age Ageing 1991;20:37-40.

10 Torrance GW, Boyle $\mathrm{MH}$, Horwood SP. Application of multi-attribute utility theory to measure social prefer-
ences for health states. Operations Research 1982;30: 1043-69.

11 Harwood RH, Gompertz PH, Ebrahim S. Handicap one year after a stroke: validity of a new scale. $\mathcal{F}$ Neurol, Neurosurg Psychiatry (in press). 


\section{Your health and your life}

This questionnaire is about the way your health affects your everyday life. Please read the instructions for each question and then ansicer by ticking the box next to the sentence which describes you best.

When answering the questions, it may help to think about the things you have done oier the last week and compare yourself with someone like you who is in good health.

\section{Getting around}

Think about how you get from one place to another, using any help, aids, or means of transport that you normally have available 1 DOLS YOUR HEAITH STOP YOL FROM (IET"TINC; AROLND?

Please tick onc box only $\square$

NOT AT Al.: $\quad$ You go everywhere you want to, no matter how far away.

VI:RY SIIIFHII: $\quad$ You go most places you want, but not all.

QLiTl A I.OT: $\quad$ You get out of the house, but not far away from it.

VIIRY MLC:H: You don't go outside, but you can move around from room to room indoors

ALMOST complETELY: You are confined to a single room, but vou can move around in it.

(:).MPIIFTHEY:

You are confined to a bed or a chair. You cannot move around at all. There is no-one to move you

\section{Looking after yourself}

Physical independence

Think about things like housework, shopping, looking after money, cooking, laundry, getting dressed, washing, shaving, and using the toilet

2 IOOSS YOLR HLALTH STOP YOL IOOKING AFTIER YOLRSELF?

Please tick one box only $\square$

\section{Nol Al al: You do everything to look after yourself.}

VI:RY SIIfiHTIY: You need a little help now and again.

QCII: A 1.01: $\quad$ You need help with some tasks (such as heavy housework or shopping), but no more than once a day

VIERY MLCII:

You do some things for yourself, but you need help more than once a day. You can be left alone

safely for a few hours.

Almosl completely: You need help to be available all the time. You cannot be left alone safely.

complatily: You need help with everything. You need constant attention, day and night.

\section{Work and leisure}

Think about things like work (paid or not), housework, gardening, sports, hobbies, going out with friends, travelling, reading,

looking after children, watching television, and going on holiday

3 DOAS YOLR HEAITH IIIIIT YOLR WORK OR IIISLRI ACTIVITIES?

Please tick one box only $\square$

NOY AT AI.: You do everything you want to do.

VERY SLIS IHTIS:

QUTH: A LOT:

You do almost all the things you want to do.

VERY MUCH:

You find something to do almost all the time, but vou cannot do some things for as long as vou would like.

ALMOST CONBL

You are unable to do a lot of things, but you can find something to do most of the time.

(OMPI.ETEIY:

You are unable to do most things, but you can find something to do some of the time.

You sit all day doing nothing. You cannot keep yourself busy or take part in any activities.

\section{Getting on with people}

Think about family, friends, and the people you might meet during a normal day

+ DOHS YOUR HEAITH STOP YOL GH"IJNC ON WTH PLOPIIE?

Nol AT AI. A :

NIRY SIIKHTIY:

You get on well with people, see everyone you want to see, and meet new people.

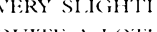

You get on well with people, but your social life is slightly limited.

VI:RY MLCH:

You are fine with people you know well, but you feel uncomfortable with strangers.

You are fine with people you know well but you have few friends and little contact with neighbours.

Dealing with strangers is very hard.

Al.Mosl completely: Apart from the people who look after you, you see no-one. You have no friends and no visitors.

(OMPII:Tl:I.Y:

You don't get on with anyone, not even people who look after you.

\section{Awareness of your surroundings}

Think about taking in and understanding the world about you, and finding your way around in it

5 DOLS YOUR HEALTH STOP YOU LNDERSIANIDIN(; THI: WORLI) AROLND YOL:

Please tick onc box only $\square$

Nol Al Al: $\quad$ You fully understand the world around you. You see, hear, speak, and think clearly, and your

memory is good.

IIRY SILFHIY: You have problems with hearing, speaking, seeing or your memory, but these do not stop you doing most things.

QLIT: A I.): You have problems with hearing, speaking, seeing or vour memory which make life difficult a lot of the time. But, you understand what is going on.

VI:RY MLCH:

You have (he/she has) great difficulty understanding what is going on.
$\mathrm{He} / \mathrm{she}$ is unable to tell where he/she is or what day it is. He/she cannot look after him/herself at all.

COMPIIFTLIY:

$\mathrm{He} / \mathrm{she}$ is unconscious, completely unaware of anything going on around him/her.

\section{Affording the things you need}

Think about whether health problems have led to any extra expenses, or have caused you to earn less than you would if you were healthy 6 ARI: YOU ABLE TO AFFORD THE THINGS YOU NIIII) Please tick one box only $\square$

YHS, IASIIY: You can afford everything you need. You have easily enough money to buy modern labour saving devices, and anything you may need because of ill health.

HAIRIY IASIIY: You have just about enough money. It is fairly easy to cope with expenses caused by ill health.

JLS

NOT RIALILY:

You are less well off than other people like you; however, with sacrifices you can get by without help.

You only have enough money to meet your basic needs. You are dependent on state benefits for any extra expenses you have because of ill health.

$x():$

You are dependent on state benefits, or money from other people or charities. You cannot afford things you need.

ABSOL.UTHIY NOT:

You have no money at all and no state benefits. You are totally dependent on charity for your most basic needs. 